\title{
Niche Markets and Small Business Strategies: \\ Shifting the Focus of International Business Education
}

\author{
Jack Scarborough \\ Barry University \\ Miami Shores, Florida
}

The purpose of this paper is to propose a shift in the emphasis of international business education, both teaching and research, in favor of small and mid-sized firms. Two established, mutually reinforcing trends suggest the need for this shift; (a) the continuing role of small business as the engine of innovation, and growth in output, export and employment creation, and (b) the continuing reluctance of many small businesses to explore export opportunities. To the extent business education serves the nation, the economy as a whole, and our international competitiveness, and what promises to be an important avenue of growth in employment opportunities for our students, we should be doing more to help small and mid-sized businesses, and let the large, capital and job exporting multinational corporations (MNCs) fend more for themselves.

Whatever store one might put into this argument now, it will become stronger as we approach the turn of the century because of a new trend which will amplify the impetus of the two trends already identified, thereby raising the incentive both for educators to emphasize smaller firms, especially international market penetration and risk reduction strategies, and for smaller firms to overcome their reluctance. This new trend is the proliferation of international niche markets as developing countries advance, creating opportunities well suited to the strategic advantages of smaller firms relative to the globalization and multicountry strategies employed by MNCs.

Examination of international business textbooks and academic journals reveal a very strong emphasis on the Fortune 500 kind of MNC. This literature addresses the problems of managing a big company trying very hard to be all things to all (very different) people, to act local while thinking global. Is this the proper focus for our efforts? Can we achieve anything more than marginal improvement? Are these the companies which are creating most of the new jobs, wealth and exports? Are we betting on "mudders" on a fast track? Why do globalization advocates support what is essentially a low-cost-leadership strategy, product driven, managed centrally, in a very complex organizational setting, when we would not consider the same recommendation for a domestic firm unless it is in a commodity business? Is the international environment so different that the concentrated, focused kind of company with a flat organization, capable of quick, flexible reaction to volatile market conditions we want to see at home irrelevant and ineffective internationally?

International markets stand to become more like our own, specifically, the eventual emergence of a middle class in developing countries begun in the newly industrialized countries of East Asia, now beginning in Latin America, and inevitably to follow in Eastem Europe and perhaps elsewhere. With a middle class must emerge the kind of market niches which will make business conditions very difficult for the big company. Before addressing these issues, it will be useful to examine typical MNC strategies. 


\section{The Globalization Strategy}

The globalized firm typically exhibits the following characteristics: (a) It seeks economies and learning curve effects from highly standardized operations, rationalized worldwide, exploiting local comparative advantages; (b) Its resources flow to any point on the globe where they can be employed most productively; (c) It obtains labor, capital and intermediate inputs and raw materials from whatever worldwide sources offer the best value; (d) In order to allocate global resources efficiently and optimize management of global operations and logistics networks, decision making tends to be centralized, even if the firm is highly dispersed geographically. Only functions which must be adapted, typically marketing, are decentralized; (e) The sheer magnitude of operations may require regional management structures, which may result in organizational complexities in melding geographical and functional responsibilities; (f) As it strives to conduct its operations, invest, and source globally, the firm tries to ignore national boundaries whenever it can; it truly looks at the world as one market, for both inputs and outputs; ( $g$ ) The basic parameter of global resource allocation is to capitalize on comparative advantages. The first rough cut is to perform labor intensive operations where labor is cheap and sophisticated operations where labor is highly skilled. The second is to optimize the trade-offs among production and logistics costs. An effective illustration of the concept is the global network of sourcing, assembly and distribution employed by automobile manufacturers which serve global requirements from regionalized production plants.

The global firm operates in what is thought to be one world of rapidly converging needs and wants, and purchase decisions based more on price and less on unique product features (Levitt 1983). Other necessary conditions include the existence of scale economies and learning curve effects in the relevant technology, and free trade to accommodate both intracompany and extra-company trade, foreign investment, and access to low-cost sourcing(Doz 1987).

\section{Globalization Strategy Weaknesses}

The globalized firm strives to establish and improve a finely-tuned, highly-integrated, maximally-optimized system of input, conversion and output processes producing massmarket, or otherwise uniform, products or services which can be sold almost anywhere. It is product driven rather than market driven. It is concerned more with efficiency than effectiveness. Its product must serve lowest-common-denominator needs, or sizable sets of such needs, i.e., "custom" mass production, such as the various versions of the Ford Escort, to generate sufficient market share to maintain cost advantages. Therefore, any force which tends to generate differentiated demand, or to neutralize cost advantages, is a threat to the globalized firm or, at best, greatly complicates its operations. 


\section{The Strategic Risks of Standardization}

The globalization strategy, by virtue of its requirement for maximum standardization and the remoteness of decision-making authority from markets, clearly is vulnerable to companies which target segments or niches. It is at once a low-cost leadership strategy and a concentration strategy, both of which expose the firm to the risks of (a) falling out of touch with customers in some way, and (b) product and/or process innovation by competitors. A low-cost-leadership strategy must be based on the assumption that buyers find price a more important purchase criterion than product or service quality or features. It seems that the number of products for which this assumption holds is diminishing (Douglas and Wind 1987). Moreover, low cost leaders face the potentially adverse consequences of not being the low cost leader. If not, they face the threat of being underpriced by the low cost leader and being outflanked by segmenters or niche finders, depending on how they stand on the various dimensions of quality. While the validity of generic strategy theory remains arguable, firms can and do find themselves "stuck in the middle." Sears, struggling for an identity, has watched low cost leader Wal-Mart become the world's leading retailer and has lost customers to more focused retailers on both ends of the market. Holiday Inns found itself under attack from both flanks and dropped out of the middle market entirely by spinning off the Holiday chain and reconstituting itself as Promus, positioned only on the flanks with Embassy Suites and Hampton Inns. Compaq found itself squeezed between the industry leaders and the I.B.M. clones. General Motors is still struggling to establish itself as a leader on either flank, with revitalized Buick and Cadillac on the quality end and the Saturn on the low-price end.

Ohmae (1990) suggests that even Japanese automakers are becoming stuck in the middle between Korean competitors and high-status European cars (although Mercedes is putting that proposition to a stiff test with the large price increases on its new S-class cars, in the face of Lexus, Infiniti and Acura). The global firm will encounter the same threats in greater numbers. If firms find themselves "stuck in the middle" in domestic markets, why should not the same thing happen to firms in international markets, where they face even more competitors? Why should management practices and strategies appropriate for the domestic goose also not work for the global gander? In other words, why should not the more focused, more concentrated, more differentiated, more responsive, more market-driven strategies which work at home not work abroad?

\section{The Multicountry Variation}

MNCs have responded to this challenge with the multidomestic or multicountry strategy, which entails decentralization of decision making and adapting any elements of the product/market strategy mix necessary to satisfy differentiated, local needs and wants. However, the multicountry organization tends to be even more complex than the global organization, with an array of product or market divisions, geographic divisions, functional subunits and matrix arrangements to coordinate its numerous, far-flung operations. This complex form is an attempt to reconcile the need for centralized control of the firm with the decentralized decision making necessary to respond to local market requirements. The 
advent of flexible manufacturing techniques allows MNCs to capture some of the benefits of greater market segmentation, but these firms still remain remote from many of their markets. Moreover, it is by no means clear that many MNCs are taking a sufficiently long term view to make the necessary investment in flexible manufacturing equipment and the highly-skilled labor necessary to operate it.

The effectiveness of globalization strategy depends on the validity of the assumptions on which it is based. Scholars have challenged all of them.

\section{Global Products}

Some notable studies (Boddewyn et al. 1986; Douglas and Wind 1987; Doz 1987; Kotler 1986; Ohmae 1990; Porter 1985; Quelch and Hoff 1986; Sheth 1986) are among the many which challenge the very notion of global products beyond some industrial and luxury goods. There are many anecdotal reports of practitioners finding difficulty accepting the idea or making it work. In response to attacks on the globalization strategy by marketing firms, Levitt said in 1988 that "Even if some local tastes are different now ... You'll find that 1992 will make a big difference" referring to ongoing European unification. Levitt added that "... the specialized brands and small market niches proliferating now (will) show up everywhere" (Lipman 1988). Yet in 1992, firms still report difficulty finding, for example, the "Elusive Euroconsumer" (Browning 1992). The preference of Japanese consumers for specifically tailored products is well known (Kang 1990 and Ohmae 1992, for example).

\section{Standardized Operations and Large Scale}

Drucker (1986) and Doz (1987), among others, question whether modern, flexible, automated manufacturing technologies require large scale, suggesting that not all industries have much to gain from globalizing. Manufacturing costs are becoming a less important component of total cost, negating some of the advantages of relocating, and scaling up, manufacturing for that purpose. Moreover, large scale and long distances make it more difficult to employ techniques such as just-in-time inventory management. Massed, globalscale plants require larger shipments over longer distance, putting upward pressure on logistics costs which rise with either increased shipment size or frequency, and with larger inventory volumes, whether enroute or on hand. Douglas and Wind (1987) suggest that variations in the relative price of alternative inputs (e.g., plastic vs. paper packaging) will vary over time, complicating efforts to standardize.

\section{Manageability and Bureaucracy}

Globalized firms normally would prefer not to localize because to do so might break down scale advantages and weaken the centralized decision making needed to optimize global systems and networks. Localization would compound the already difficult problem of managing MNCs, already broken down into various, often complicated, combinations and layers of geographical, functional and product/market divisional subunits or matrices. Even 
without locally decentralized subunits, it is not yet clear that any form of global corporate structure can be managed effectively, even if managed efficiently (Doz 1987; Doz and Prahalad 1981; Prahalad and Doz 1981). The complicated MNC structure, together with its centralized decision making, appears even more risky in the face of a manifest need for speedy decisions engendered by accelerating evolution of markets and shorter product development cycles.

Global firms will become increasingly exposed to the threat of advancing product and process technologies. As a global firm becomes locked into an optimized high-volume, highefficiency mode, it becomes more vulnerable to technological advances. The U.S. as a nation suffered this fate at the hands of the Japanese, who are now looking over their shoulders at the Asian tigers and, in the long run, the Peoples' Republic of China. More recently, who could have imagined how fast personal computers would become a commodity-like product? The portability of technologies like CAD-CAM increases the number of potential innovators and hastens their rate of advance.

If globalization is based on sound theory, then firms may indeed be able to optimize production of "world" products, and accept some isolation from their markets. But that has not been the case even in domestic markets. The imperative to "build a better mousetrap" may be inconsistent with the very idea of globalization. Will a globalized firm be able to match the innovations of smaller, more agile competitors? Will it recognize the need to do so? Will it be able to react quickly enough if it does recognize the need?

An optimized system is often an inflexible one in human terms as well as technologically. The investment of so much effort and capital in existing organizational configurations and relationships causes behavioral and financial resistance to change. Highly centralized structures delay and dilute decision making, causing ineffective responses and lost opportunities. Many firms are working hard to become more responsive, quicker to react, more sensitive to changing needs and wants. The importance of technology highlights the need for flexibility. Even if one's customers do not change, one's competitors will continue to search out better ways to serve them. Globalization itself serves to increase the number of competitors, all of whom are potential innovators trying to make one's business obsolete, while weakening the global firm's ability to match them. Recall how badly Japan's more rapid product development cycle hurt U.S. automobile makers. Firms must be prepared to counter substitute products not yet conceived or brought to market. Bureaucracy seems to grow like weeds; unwanted, unintended, but prolific nonetheless. Is there any reason to presume that whatever dysfunctions afflict conventional firms will not afflict global ones, and on a global scale at that?

\section{Free Trade}

The global strategy is associated with a borderless world and the triad megamarkets (Ohmae 1990; 1985), i.e., a strategy requiring a firm foundation in the three great markets to build sufficient scale to compete effectively in those markets as well as in other, smaller markets. The extent of free trade more or less accommodates that strategy today, but that may not remain so. The prognosis for global, as compared to regional or bilateral, free trade is 
mixed at best. Even as the world tries to converge economically, there remains sometimes violent political divergence, which will be exacerbated by periodic declines in economic activity. Already existing and reemerging nationalism, extremism and zealous religious factions are fractionating forces which sustain and even heighten cultural differences.

The emergence of trading blocs may well make the situation worse. These blocs could shrink global horizons to hemispheric (enterprise for the Americas), continental (European Community) or even regional (e.g. East Asian) dimensions. A reduced opportunity to move the factors of production across borders is a major threat to globalization and thus a strong incentive to localize. While regional integration threatens the global strategy, it still accommodates the regional and, obviously, the local strategy. The stronger international competitors the Europeans are trying to create by unifying their market will intensify competition elsewhere, generating more pressure on firms to carve out defendable niches. If Japan, perhaps because it might be excluded from, or inhibited in, Europe or the Western Hemisphere, establishes a yen-based bloc in East and Southeast Asia, those markets will not be large enough to support Japan's export requirements. Thus, where local markets do remain open, and it will be very much in their interest to do so, the competition stands to become quite intense. The upside potential of the General Agreement of Tariffs and Trade (GATT) may well depend on its ability not only to break its present deadlock, but to forge a link among these emerging trading blocs. This kind of highly competitive environment, in markets with more differentiated requirements, should be highly susceptible to niche strategies.

The vulnerabilities inherent in the assumptions on which the globalization construct is grounded have been masked by the large proportion of trade by globalized MNCs among developed countries (DCs), which have markets large and diverse enough to absorb all kinds of products, even if undifferentiated, as long as they conform to Levitt's prescriptions that such products offer both high quality and low price. Moreover, despite the requirement that global products offer low price, it is probably more correct to say that successful global products are relatively high-priced or even luxury goods, produced at relatively low costs afforded by economies of scale (Boddewyn et al. 1986; Douglas and Wind 1987). This would account for the success of the globals in LDCs, where there is almost always a market for high-end goods, now matter how poor the country.

\section{Performance}

The first major empirical study of the impact of global standardization in terms of financial performance, reported in the Journal of Marketing, does not support the superiority of the globalization strategy (Saimee and Roth 1992). This study of 147 business units in twelve industries, $85 \%$ of which manufacture industrial products (i.e., those usually deemed very susceptible to standardization), found no significant advantage in financial performance for firms employing global standardization strategies in the most recent three-year period. The authors concluded that any cost advantages associated with standardization are probably offset by the effects of price competition in global markets. This finding is consistent with the expectation that firms which target the mass market expose themselves to niche finders who can target more discriminating and hence more lucrative segments, leaving the larger, 
standardized firms with increasingly commodity-like products which must compete primarily on price. In essence, the strategic risk of globalization is that it is a low-cost- leadership strategy, relying on cost advantages based on scale and bargaining power, and the threat of massive retaliation and cross subsidy to deter new entrants. This offers the downside potential of frontal-assault price wars as these large firms compete to cover their large overheads. If the study is correct in that standardization does not necessarily yield improved returns, then it seems difficult to justify pursuit of this strategy with its attendant limitations and risks.

\section{An Upper Limit on Globilization?}

A basic premise of this paper is that improving business, economic, financial and political conditions in LDCs will accelerate development in those countries in the next decade, and that these improved conditions will generate opportunities for mid-size and small U.S. firms to export to those markets. These opportunities will manifest themselves in the form of greater market segmentation which will accompany rising standards of living, most likely to emerge first in Latin America. Should that prove to be the case, the demand for differentiated goods should grow faster than the market for standardized goods, shifting demand in favor of more focused, specialized firms and exacerbating the weaknesses of the globalized company and the less effective multicountry companies. Given that this argument remains somewhat speculative at this point, it will be developed in a series of propositions which, if tested and found valid, will serve to support it.

$P_{1}$ The ongoing shift in manufacturing employment from DCs to LDCs eventually must begin to consume excess labor supplies and drive up wages, incomes and consumption in those LDCs.

$P_{2}$ This transfer will promote entrepreneurship and initiative manifested in the development of supporting industries and stimulate local competition, which in turn will amplify wealth creation.

More manufacturing means not only higher disposable income, but development of local human and capital infrastructure, expansion of intermediate product, service and distribution industries, and the foundation for industrialization. In effect, the developing countries will begin developing faster, and become, necessarily, more developed, exhibiting the more statistically normal income distribution characteristic of a developed country, in effect, the LDCs will develop a middle class. Therefore, as an LDC more resembles a DC, the more effective product and market strategies employed in DCs, i.e., differentiation, should become more effective in LDCs. The MNCs are transferring technology, skills and experience to LDCs and, perhaps most significantly, models for local entrepreneurship.

$\mathrm{P}_{3}$ Improved macroeconomic, financial and political conditions in LDCs will draw more foreign investment and induce the return of flight capital which will finance development of primary and secondary industries. 
The health of local capital markets and the competitiveness of local firms will be enhanced by the return of flight capital and increased foreign investment encouraged by improving financial and political stability in LDCs, especially in Latin America. Perceived risk is being reduced by a shift in policy from import substitution to export promotion and free trade. This shift is manifested in more democracy, privatization of state-owned enterprises, reduction of debt burdens and inflation, lowering of barriers to trade and investment, and growing equity markets. Trade with Latin America and trade within and among the newly invigorated trading blocs in South America is booming. Mexico's recent actions and positive results are the most salient example. When Mexico enters the North American Free Trade Agreement, Chile and much of the rest of Latin America should follow, thereby accelerating this trend.

$\mathrm{P}_{4}$ Rising income levels will generate more market segments which will, in turn, generate demand for more differentiated products, especially consumer goods.

The emergence of a middle class accommodates more income levels and concentrates more wealth and purchasing power in what will become much larger lower-middle and middle-income groups. New consumers will generate more volume and diversity in the demand for goods and services than either the poor lower classes or very small wealthier classes which together formerly constituted the "two-humped" income distribution of the typical LDC. With greater wealth should come increased buyer sophistication and discrimination, and thus a taste for differentiated products. Increasing travel and education levels will intensify this trend.

If we do see significantly rising incomes in LDCs in the coming years, then we know what to expect. New market niches should proliferate not only among more and larger middle income groups, but across new lifestyles and ethnic groups (Douglas and Wind 1987). Weakening social norms should develop segments across generations. Newly emergent purchase criteria such as novelty and conspicuous consumption will encourage differentiation (Sheth 1986).

Thus, an improved standard of living allows more choice, creating new, divergent needs and wants in societies formerly dominated by two segments, rich and poor. One-time subsistence workers will enjoy new opportunities to improve their individual standards of living, and in so doing exercise their individual tastes and preferences. More differentiated consumer demand should in turn generate more differentiated demand for intermediate products by local producers, thereby providing more opportunity for intermediate or industrial goods makers. Anecdotal evidence suggests that this process has already begun in Mexico, where rising incomes, shortages in some worker categories, and more discriminating consumer demand are being reported (Perry, 1992). Indeed, it now appears that Latin America will be the next region to make the transition to industrialization (Baker et al.1992a; 1992b; Martinez et al. 1992).

These trends will accelerate existing forces favoring unique products. Perhaps $80 \%$ of international products require some adaptation while the average product requires substantial 
adaptation. Many international product failures are attributed to inadequate adaptation (Kotler 1986). An overly standardized product/market mix stifles innovation, inventiveness and responsiveness (Kashani 1987). Many global product buyers tend not to be price sensitive, and so-called world products tend to be luxury goods. Research findings and PIMS data indicate that uniqueness is increasing in importance as an international marketing tool (Douglas and Wind 1987).

\section{Strategic Implications}

$\mathrm{P}_{5}$ Not only global MNCs, but even multicountry MNCs are vulnerable to niche finders.

The prevailing wisdom holds that the large MNCs, aided by their ability to crosssubsidize, will continue to dominate international markets. For all the reasons noted above, the utility of the pure global MNCstrategy is limited. The more effective multicountry MNCs are much better positioned and skilled in their ability to target newly emerging market segments. This competitive advantage should precipitate a shift in market share in their favor as LDC economies advance. But these firms have their weaknesses as well. Even MNCs which have sought to localize will suffer competitively relative to local niche players because of the MNCs' larger overheads, slower response, and less thorough knowledge of local markets.

$\mathrm{P}_{6}$ Even if the MNCs continue to dominate international markets, they cannot defend them all.

If international market behavior replicates our domestic markets, the inevitability of successful niche finders is certain. Increasing segmentation of markets puts large companies on the defensive, just as flanking or guerilla forces put superior armies on the defensive. With due respect to Clausewitz, the great flaw of the defensive is that the larger one's territory, or market share, becomes, the more difficult it is to defend, because attackers can concentrate, or focus, their resources while the defender cannot. The defender must try to occupy and fill all gaps, stretching even superior resources too thinly, leaving itself exposed somewhere. The clever and determined niche finder will find and exploit those gaps. The challenge for America, and American business education, is to provide our potential niche finders the necessary wherewithal and the determination, even as our MNCs improve the employment and trade balances of other nations.

\section{A New Educational Framework}

Much of our research and pedagogical material deals with the structuring and operation of large MNCs, with emphasis on how MNCs need to localize while remaining basically global. This argument goes largely unquestioned, despite the increasing irrelevance of standardization in our own market. But evolving market conditions seem to suggest that we 
should devote less attention to Fortune $500 \mathrm{MNCs}$ and more to our middle-market and smaller firms. This would be particularly so for schools which teach students employed not by the Fortune 500, but that much more dynamic, larger, faster growing, employmentcreating, and perhaps even more interesting mass of smaller firms. Except for our most elite schools, it would seem that most international business students are destined for these smaller firms.

Even if the hypothesis offered here proves totally unfounded, we still are remiss if we let any firm move toward greater rigidity, standardization and less responsiveness to customers, no matter how clever the techniques we devise to cope with the globalizationlocalization dichotomy, without raising caution flags. By not doing so, we would be letting businesses make the same mistakes internationally that they made at home, in a competitive environment much less forgiving than our own. The stakes of international competition are too high to risk such an error. Conversely, the encouragement of smaller businesses to engage internationally would serve to focus the efforts of the most creative and energetic of American firms in a direction which can only improve our competitiveness. To focus only on global MNCs and their problems may be too narrow an approach to international business education. Moreover, it may be self-defeating; as our MNCs continue to export jobs, where will our students find jobs? The answer lies with where we should refocus our efforts, with our smaller firms. Entrepreneurship is our national comparative advantage; we must exploit it more effectively and completely. Let us leave the dangerous, commodity-like markets to others and strive for the entrepreneurial markets which best suit our innovativeness, psychological orientation and business and cultural values.

We should redirect our thoughts, our research, and our teaching to improving our support for, and the competitiveness of, smaller firms. We should be emphasizing practical skills, teaching our students how to do international market research, where and how to find assistance from governments, financial institutions, trade associations and trade centers, and middlemen. We should prepare them to help middlemarket and small firms build the skills and confidence they need to recognize and evaluate international opportunities, overcome risk, and to plan and commit themselves to the long term. The strategies small firms should employ are well established. Happily, and a basic point of this paper, what will work best is what small firms do best, i.e., well-executed, focused strategies. This is how small firms competed successfully against large firms at home, and what they must do well to take on the MNCs. We certainly can teach it and they clearly can do it. What is more difficult is generating the enthusiasm and commitment in risk-averse small firms and, what must go beforehand, shifting our own priorities as educators.

International business educators should shift from efforts to improve MNC performance, which results in only marginal improvement of company performance and little benefit for our economy, to improving small business exports which can lead to much more significant improvements on both scores. This involves changing our dispositions from:

(a) optimizing global systems to optimizing exports,

(b) the theoretical to the practical,

(c) thinking global to thinking local, 
(d) emphasis on corporate strategy to business-level strategy,

(e) managing investments to managing companies,

(f) East-West trade to North-South trade,

(g) consulting with the Fortune 500 to consulting with the agencies, institutions and organizations which promote the interests of small business, and, for smaller schools, with small companies directly, and

(h) researching MNC behavior to researching LDC consumers and niche markets, and export channel behavior.

\section{Research Needs and Expectations}

Realization of the basic premise of this paper, that industrialization will lead to greater segmentation of markets, requires little more than continuation of similar processes which have already occurred in developed countries and are ongoing in newly industrialized countries such as Taiwan and South Korea, even though those countries have relatively homogenous cultures. Nearby Mexico may provide a real-time laboratory to test a hypothesis regarding the proliferation of segments with rising incomes. Prior research suggests that the kinds of consumer goods used in the home should provide the most immediate results (Quelch and Hoff 1986).

The greatest vulnerability in this entire argument may be the notion embodied in proposition one, that the shift in manufacturing employment from DCs to LDCs eventually must begin to consume excess labor supplies and drive up wages, incomes and consumption. The nature of the vulnerability lies in the word "eventually;" in that the poor, unemployed populations in LDCs are so large that it may be many years before incomes rise to the extent that a middle class and, with it, a proliferation of income-based segments, develops. In other words, the real issue here is not "if," but "how soon." Hence, it is not the validity of this proposition that is in question as much as the timing. The same logic applies to proposition two, regarding development of entrepreneurship and supporting industries, and proposition four, regarding generation of more market segments and greater demand for more differentiated products. Historical patterns of market segmentation in newly industrialized countries might shed some light on this issue.

The flow of new and returning capital into LDCs which demonstrate the resolve and pursue the correct policies to reduce structural problems, such as Mexico, Chile and Argentina, is underway. Open questions include whether (a) the political changes attracting capital will continue and (b) capital markets function efficiently. If so, proposition three is valid.

Proposition five, which suggests that even multicountry MNCs are vulnerable to niche finders, may understate the will or ability of multicountry MNCs to target emerging niches sooner or more effectively than smaller exporters. The resolution of this issue depends on timing, just as does the basic premise of this paper. The longer it takes for new market segments to develop, the more time the MNCs will have to make the necessary adjustments. This suggests an urgent need is to get our smaller firms moving as soon as possible to take advantage of what may be a limited window of opportunity. We can help our smaller 
exporters most in this regard with finely honed market research techniques which can detect early signals of emerging segments or lucrative product line voids.

Proposition six says that even large companies cannot defend all niches. Our domestic experience bears this out in one industry after another. This proposition may well be the most important point in this entire argument.

\section{References}

Baker, Stephen, Elizabeth Weiner, Geri Smith, Ann Charters, and Ken Jacobson. 1992a. "Latin America: The Big Move to Free Markets." Business Week (June 15): 50-55.

Baker, Stephen, Ken Jacobson, Elizabeth Weiner, and Geri Smith. 1992b. "Brave New Financial World: Investors in Latin America Are Betting the Region Can Only Grow." Business Week (June 15): 60-62.

Boddewyn, J. J., Robin Soehl and Jacques Picard. 1986. "Standardization in International Marketing: Is Ted Levitt in Fact Right?" Business Horizons 29 (November-December): 69-75.

Browning, E. S. 1992. "In Pursuit of the Elusive Euroconsumer." The Wall Street Journal (April 23): B1, B8.

Douglas, S. P. and Y. Wind. 1987. "The Myth of Globalization." Columbia Journal of World Business 22 (Winter): 19-29.

Doz, Y. 1987. "International Industries: Fragmentation Versus Globalization." in Technology and Global Industry. Eds. B. K. Guile \& H. Brooks. Washington: National Academy Press: 96-118.

Doz, Y. and C. K. Prahalad. 1981. "Headquarters Influence and Strategic Control in Multinational Companies." Sloan Management Review 23 (Fall): 15-29.

Drucker, P. F. 1986. "The Changed World Economy." Foreign Affairs 64 (Winter): 768-791.

Kang, T. W. 1990. Gaishi: The Foreign Company in Japan. New York: BasicBooks.

Kashani, Kamran. 1989. "Beware the Pitfalls of Global Marketing." Harvard Business Review 67 (September-October): 91-98.

Kotler, Philip. 1986. “Global Standardization-Courting Danger.” Journal of Consumer Marketing 3 (Spring): 13-15.

Levitt, T. 1983. “The Globalization of Markets.” Harvard Business Review 61 (May-June): 92-102.

Lipman, Joanne. 1988. "Marketers Turn Sour on Global Sales Pitch Harvard Guru Makes." The Wall Street Journal (May 12): 1, 13. 
Fall 1993

Martinez, Jon I., John A. Quelch, and Joseph Ganitsky. 1992. "Don't Forget Latin America." Sloan Management Review 33 (Winter): 78-92.

Ohmae, K. 1990. The Borderless World: Strategy and Power in the Interlinked Economy. New York: HarperBusiness.

Ohmae, K. 1985. Triad Power-The Coming Shape of Global Competition. New York: Free Press.

Perry, Nancy J. 1992. “What's Powering Mexico's Success?” Fortune (February 10): 109-115.

Porter, M. E. 1985. Competitive Strategy: Techniques for Analyzing Industries and Competitors. New York: Free Press.

Prahalad, C. K. and Y. Doz. 1981. "An Approach to Strategic Control in Multinational Companies." Sloan Management Review 22 (Summer): 5-14.

Prahalad, C. K. and Y. Doz. 1987. The Multinationals' Mission. New York: Free Press.

Quelch, John A. and Edward J. Hoff. 1986. "Customizing Global Marketing." Harvard Business Review 64 (May-June): 59-68.

Samiee, Saeed and Kendall Roth. 1992. "The Influence of Global Marketing Standardization on Performance." Journal of Marketing 56 (April): 1-17.

Sheth, Jagdish. 1986. "Global Markets or Global Competition?" Journal of Consumer Marketing 3 (Spring): 9-11. 